\title{
Tailored Nutrition Education and Food Assistance Improve Adherence to HIV Antiretroviral Therapy: Evidence from Honduras
}

\author{
Homero Martinez - Kartika Palar · Sebastian Linnemayr • \\ Alexandria Smith • Kathryn Pitkin Derose • \\ Blanca Ramírez · Hugo Farías · Glenn Wagner
}

Published online: 1 May 2014

(C) Springer Science+Business Media New York 2014

\begin{abstract}
Food insecurity and malnutrition negatively affect adherence to antiretroviral therapy (ART) and are associated with poor HIV clinical outcomes. We examined the effect of providing household food assistance and nutrition education on ART adherence. A 12-month prospective clinical trial compared the effect of a monthly household food basket (FB) plus nutrition education (NE) versus NE alone on ART adherence on 400 HIV patients at four clinics in Honduras. Participants had been receiving ART for an average of 3.7 years and were selected because they had suboptimal adherence. Primary outcome measures were missed clinic appointments, delayed prescription refills, and self-reported missed doses of ART. These three adherence measures improved for both groups over 12 months $(p<0.01)$, mostly within 6 months. On-time prescription refills improved for the FB plus NE group by $19.6 \%$ more than the group receiving $\mathrm{NE}$ alone after 6 months $(p<0.01)$, with no further change at 12 months. Change in missed appointments and self-reported missed ART doses did not significantly differ by intervention group.
\end{abstract}

H. Martinez $(\bowtie) \cdot$ K. Palar · S. Linnemayr · A. Smith .

K. P. Derose · G. Wagner

RAND Corporation, 1776 Main St., Santa Monica, CA 90401,

USA

e-mail: homero@rand.org

H. Martinez

Hospital Infantil de México "Dr. Federico Gomez",

Mexico City, DF, Mexico

K. Palar

Fielding School of Public Health, University of California,

Los Angeles, CA

B. Ramírez · H. Farías

United Nations World Food Program, Regional Office for Latin

America and the Caribbean, Panama City, Panama
Resumen La inseguridad alimentaria y la malnutrición afectan en forma negativa la adherencia a la terapia antiretroviral (TAR), y se asocian con malos resultados clínicos relacionados con el VIH. En este estudio examinamos el efecto de ofrecer una canasta de ayuda alimentaria (CA) y educación nutricional (EN) sobre la adherencia a la TAR. Mediante un ensayo clínico prospectivo a nivel de conglomerados, comparamos el efecto de una CA para la familia ofrecida en forma mensual adicional a EN en contraste con EN por sí sola sobre la adherencia a la TAR en 400 pacientes infectados con VIH, en cuatro clínicas en Honduras. Los participantes habían estado recibiendo TAR por un promedio de 3.7 años, y fueron elegidos con base en mostrar adherencia sub-óptima a la misma. Las medidas de impacto incluyeron número de citas clínicas perdidas, retraso en surtir los medicamentos, y el auto-reporte de dosis faltantes de TAR. Las tres medidas mejoraron en ambos grupos a lo largo de 12 meses de seguimiento $(p<0.01)$, con la mayor parte del efecto observado en los primeros 6 meses. El surtimiento de medicamentos en la farmacia mejoró $19.6 \%$ más en el grupo que recibió CA más EN en comparación con el grupo que recibió sólo EN, a los 6 meses de seguimiento $(p<0.01)$, sin mayor cambio a los 12 meses de seguimiento. En cuanto a citas clínicas perdidas y el auto-reporte de dosis faltantes de TAR, no hubo una diferencia significativa al comparar entre ambos grupos.

Keywords HIV · Food security · Food aid · Nutrition education $\cdot$ ART adherence $\cdot$ Latin America

\section{Introduction}

Food insecurity and malnutrition pose barriers to antiretroviral treatment (ART) adherence in resource-poor settings, 
and are often cited by patients, providers, and HIV treatment advocates as main obstacles to accessing and adhering to ART treatment [1-5]. Some antiretroviral medications must be taken with food [1] and people who begin treatment but cannot follow food and nutrition recommendations are likely to have increased drug side effects that create significant discomfort or even inhibit eating, which may lead to treatment interruptions or discontinuation. Poor nutrition also affects the efficacy of drug metabolism [6]. Treatment adherence includes taking the correct dose of each drug prescribed, at the correct time and according to physician's recommendations, following through on appointments, and staying engaged with clinical care and monitoring. ART requires regular medical visits, which involve transport costs and lost work time, thereby reducing household monetary resources available for food acquisition. Poor adherence, in turn, leads to treatment failure and development and spread of drug resistance. Food insecurity can lead to trade-offs between treatment adherence and other subsistence needs [4, 7, 8]. Therefore, promoting food security and effective nutritional support are crucial to ensuring optimal ART uptake, adherence, and outcomes.

Individual or household food aid is among the evidencebased strategies to improve adherence [9, 10]. However, evidence for this recommendation comes mainly from a few studies in sub-Saharan Africa [11, 12]. Meanwhile, over the last 10 years, the World Health Organization (WHO) and other international organizations have issued recommendations that HIV-infected individuals should consume a diet that is nutritionally adequate rather than to rely on high-dose supplements of vitamins and minerals [13]. Likewise, nutritional assessment and dietary counseling are promoted as the best standard part of comprehensive care for HIV [1416]. International organizations, including the United Nations (UN) World Food Program (WFP) and the UN Food and Agriculture Organization, have therefore implemented diverse interventions to address food insecurity and malnutrition among people living with HIV (PLHIV), including nutritional counseling and education and household food aid [11, 17-19]. The overall hypothesis is that providing a supplemental food ration will improve adherence by easing household resource constraints and increasing food availability to the person receiving ART. However, there is not enough information about the impact of these food and nutrition interventions on ART adherence. Further, evidence on whether food security and nutritional interventions improve adherence remains underdeveloped, especially for regions outside sub-Saharan Africa.

We implemented a pilot intervention with people receiving ART in Honduras to test the effects of provision of a household food basket plus nutritional education sessions on ART adherence compared to nutritional education alone. The study was conducted in collaboration with the
UN WFP in Latin America, the Ministry of Health in Honduras, four government HIV clinics, and civil society represented by the Association of People Living with HIV/ AIDS in Honduras (ASONAPVSIDAH).

\section{Methods}

\section{Study Design}

We conducted a prospective clinical trial to compare the effects of a food basket plus nutrition education versus nutrition education alone on ART adherence in Honduras. At the time of the study, the Honduras National AIDS Plan [20] included recommendations for nutritional assessment and education as best practices for HIV care, although such services were not yet offered at any of the 36 governmentrun HIV centers in the country, including our study sites. Given the standard of care recommended by the National AIDS Plan, we considered it would be unethical to not provide such services, so we offered nutrition education to all participants in the study, which provided us an active comparison group. We then assessed the additive effect of the household food basket, above and beyond nutrition education alone.

\section{Study Sites}

In collaboration with participating institutions, we selected two regions in the country with similarly high levels of HIV infection (namely, the capital city of Tegucigalpa and the Caribbean region) and selected two HIV Comprehensive Care Centers in each region, all of them located within government-run hospitals. The hospitals were chosen so they would be comparable in size (two large hospitals in the capital city and two small hospitals in the Caribbean region), number of HIV patients, number of patients on ART, and drop-outs. At the time of randomization, Hospital del Tórax in Tegucigalpa was a public hospital that served 1,504 people with HIV/AIDS and had 688 patients on ART. On average, 31 patients with HIV were seen on a regular day, with 25 patients starting on ART each month, and 10 patients dropping out from the ART program each month. Hospital Escuela, also in Tegucigalpa, served 688 patients with HIV/AIDS, with 485 registered patients under ART. On average, 32 patients were seen at the outpatient clinic every day. Thirty patients started receiving ART each month, and 10 patients dropped out of the ART program each month. In the Caribbean region, Hospital de Progreso had 356 patients with HIV/AIDS, with 227 registered receiving ART, and 11 outpatients seen per day. An average of 4 patients started receiving ART each month, and 4 patients dropped out of the ART program each 
month. Also in the Caribbean coast, Hospital de Tela had 309 participants with HIV/AIDS, 242 under ART, and an average of 12 outpatients per day. On average, 3 patients started receiving ART each month, and 1 patient dropped out of the ART program each month. Each pair of hospitals shared similar socioeconomic characteristics in the region.

\section{Randomization Procedure}

With all interested stakeholders (i.e., Ministry of Health, WFP, ASONAPVSIDAH and researchers) present to assure transparency and fairness, the paired study centers were randomly assigned by means of a coin toss to the intervention, such that two clinics (one large and one small) provided the food basket plus nutritional education intervention to study participants, and the two others provided only nutritional education. Randomization at the individual participant level was ruled out because we considered it unethical to withhold the food basket to eligible study participants within the same clinic. Furthermore, it was agreed that the population recruited in clinics initially assigned to NE would receive the food basket once data collection was completed.

\section{Patient Recruitment}

In collaboration with the clinical staff in each Center, a trained study nutritionist screened daily the clinical charts of patients who attended the clinic. Inclusion criteria for the study were: being 18 years old or older; being a local resident of the community for more than 1 year; receiving ART for at least 6 months, with indications of suboptimal adherence (i.e. missed clinic appointments, delayed pharmacy refills, or self-reported missing medication doses); being underweight $\left(\mathrm{BMI} \leq 18.5 \mathrm{~kg} / \mathrm{m}^{2}\right)$ and/or demonstrating present household food insecurity. Exclusion criteria included being unable to speak and understand Spanish or having plans to move in the next year. Pregnant women meeting eligibility criteria received the food basket, but were excluded from the study to avoid the confounding influence of pregnancy on change in nutritional outcomes. The nutritionist approached patients who met the eligibility criteria to introduce the study and invite them to participate. Those who accepted provided informed, written consent (with accommodations made for those with low literacy). The recruitment period lasted between December 2009 and October 2010, until the sample size was met (130 participants in each of the large centers, 70 participants in each of the small centers). Participants were provided with a monetary incentive to cover transportation costs, equivalent to $\sim \$ 5$ USD in local currency (about $36 \%$ of the daily minimum wage), after completion of each survey at baseline and months 6 and 12 (up to $\$ 15$ total). RAND's Human Subjects Protection Committee, as well as Honduras' National Bioethics Committee based at the National Autonomous University of Honduras, approved the study.

\section{Nutritional Intervention}

Four nutritionists participated in the design of the nutrition education component of the study, which was based on extensive formative research preceding the intervention, a comprehensive review of available nutritional guidelines for PLHIV developed for different regions [21-23], and adaptation to the local context based on expert's advise. During the formative phase, we collected information on food consumption habits of PLHIV and evaluated their macro- and micronutrient intake and nutritional status, as well as the cultural acceptability, local availability and price accessibility of foods. One nutritionist was in charge of each site, including delivering the intervention and carrying out all study assessments.

\section{Food Basket}

Participants received a monthly household food basket provided by WFP, that they or a family member picked up from the hospital or other community location at a fixed time. Following regular WFP procedures, the food basket was offered to each participant for a 12-month consecutive period. The contents and quantity of food provided were calculated for a household of five people for 30 days, and included the following daily portions: $1,000 \mathrm{~g}$ of maize, $240 \mathrm{~g}$ of rice, $370 \mathrm{~g}$ of beans, $500 \mathrm{~g}$ of fortified corn-soy blend, and $90 \mathrm{~g}$ of vegetable oil. The overall monthly cost of this basket was \$46 USD. According to WFP's policies, providing a household food basket rather than an individual food ration was intended to avoid diversion of the food meant for the ART patient to other uses such as sharing with the family. WFP kept track of how many individuals/ families were being supported by the project, and provided transportation and storage for the food rations from a central location in each study area to the distribution center. Study nutritionists managed the food distribution process with the participation of ASONAPVSIDAH to ensure that all study participants received their rations. The food baskets were distributed on a fixed day of the month at the participating hospitals or a nearby location where the food rations were stored. It was impractical to time pickup to each participant's clinic appointment, and storage was not always available at the clinics. At the end of the field phase, all participants who were initially assigned to the $\mathrm{NE}$ only group also received the food basket, in the same amount and for the same period as previously described. 


\section{Nutrition Education}

A nutrition education curriculum with supportive visual aids and a reference technical manual was developed by the team nutritionists to assist in delivering the intervention in a standardized fashion. The nutrition education sessions followed a two-pronged approach. On the one hand, each individual received a 20-min one-on-one counseling session as part of the regular monthly assessment. These sessions followed a comprehensive curriculum, starting with an introduction to the importance of nutrition, a general overview of nutritional concepts (including macro and micronutrients), a simple and easy to understand classification of foods according to their main nutrient content, how to balance a diet based on locally available foods within budget, and what foods to eat under specific circumstances (i.e., diarrhea, oral ulcers, etc.). This core 5-session curriculum was meant to be covered within 6 months (allowing for one missed session), and was reviewed twice during the 12 months of the study. Comprehension of each nutrition education session was reviewed by verification questions and reinforced by take-home pamphlets that helped participants remember the key concepts discussed. These individual sessions were complemented by monthly 1-h group sessions also led by the nutritionists. These sessions were highly participatory, using activities and games to engage participants and elicit answers to "challenge questions" that reinforced concepts such as which nutrients are included in specific foods. To foster participation, sessions included cooking activities and practical demonstrations. All nutrition education activities were designed for participants with low literacy. Participants were expected to attend at least five group sessions during the 12-month intervention period.

\section{Theoretical Model for Behavior Change}

Following the three constructs comprising the informationmotivation-behavioral skills model (IMB) [24, 25], we expected that nutrition education provided to all study participants would improve ART adherence by: (1) providing information about the importance of and how to obtain an adequate nutritional status to stay healthy and minimize side effects, such as nausea, (2) motivating participants to maintain good nutrition and adherence, reinforced by family members, and (3) providing the behavioral skills to improve eating habits.

\section{Measures}

Study measures were assessed at baseline, 6 and 12 months.

\section{Outcomes}

Adherence We used three complementary, binary measures of adherence, including two objective measures (poor clinic attendance and delayed prescription refills) and one subjective measure (participant self-report of having missed doses). Poor clinic attendance was abstracted from the patient's medical chart and defined as having missed any scheduled clinic appointments in the past 6 months. Having delayed prescription refills was abstracted from the clinic's pharmacy data and defined as the patient being late (i.e., over 1 week) to refill any monthly ART prescriptions in the past 6 months. Having missed ART doses was assessed during the nutritionist-administered interview during where patients were asked whether or not they had missed taking their ART medication for any length of time in the past month.

Food Security, Anthropometric Measurements, Dietary Intake These variables were collected as part of the overall trial, but are reported elsewhere, so no further mention of them will be made in the present paper [26].

\section{Covariates}

We included demographic, clinical, health, and socioeconomic characteristics that the literature suggests may confound the relationship between receiving a nutritional intervention and adherence [27-30].

\section{Demographic Characteristics}

Demographic characteristics included gender, self-reported Afrodescendent race/ethnicity, age, household size, children under 18 living in the household, and whether the participant had completed at least primary school.

\section{Clinical Characteristics}

CD4 cell count was abstracted from the patient's medical chart at baseline; however, given significant missing data for this variable, a binary variable for presence of HIV symptoms (such as opportunistic infections) abstracted from the patient's medical chart was used to measure HIV clinical health. The date of ART initiation was abstracted from the medical chart to calculate the amount of time receiving ART.

\section{Health Status}

Weight and height measurements were assessed according to accepted methods [31] and used to derive body mass index (BMI). BMI was used to classify the nutritional status of participants according to international standard definitions [32]. Depressive symptoms were measured using the 9-item Patient Health Questionnaire (PHQ-9) [33]. Items were summed with a possible range of 0-27, with scores $>9$ corresponding to major depression. 


\section{Socioeconomic Characteristics}

Food insecurity was assessed using the validated Latin American and Caribbean Food Security Scale [34], and categorized as none, mild, moderate or severe. Participant socioeconomic status was assessed through three binary variables: completed at least primary school; worked in the last month; and currently receiving economic support from a relative, friend or other non-institutional source.

\section{Analysis}

We first used bivariate statistics (Chi square test, two sample $t$ test) to compare the baseline characteristics of the food basket plus nutrition education group to the nutrition education group. We then conducted multivariate longitudinal regression analysis to investigate the effect of the interventions on each of the three adherence outcome measures in separate analyses. The main independent variables were binary variables for the 6- and 12-month assessments (to capture the overall time trend) and an interaction term of intervention group by each assessment time point to capture whether effects changed over time within each group. Since both groups received nutrition education, the coefficients on the interaction terms represent the added effect of the food basket above and beyond nutrition education.

We specified our regressions using a linear probability model (LPM) in order to ease interpretation of the interaction term 'Food basket $\times$ Month $t$ ', i.e., our main program effect variable. While non-linear models (such as logit or probit) are typically used for binary outcome variables, they are more difficult to interpret with respect to any interaction terms included, motivating some analysts to prefer LPM [35]. We also ran non-linear regressions as a robustness check; the results did not differ significantly from LPM, so we do not present them here. All regressions were implemented using generalized estimating equations for analysis of correlated repeated measurements [36] and semi-robust standard errors in STATA/IC 11.1 (StataCorp: College Station, Texas).

We controlled for baseline characteristics that could potentially confound the outcomes, including age, gender, education, work status, presence of children in household, food insecurity score, BMI, HIV symptomatic status, material support from family and friends, depression, and a set of interview month indicators to control for seasonality. In addition, we included attrition weights to account for dropout from the study, which were derived via logistic regression using completion status as the outcome and baseline measures associated with completion status and intervention assignment as the independent variables. For all statistical analyses, results were considered statistically significant at $\alpha=0.05$. However, we also considered results at $\alpha<0.10$ of interest, given our small study size and the exploratory nature of our aims.

To account for any missing adherence data at baseline that may cause an upward bias in our results, we conducted sensitivity analyses using an intuitive, "worst-case scenario" approach as an alternative to multiple imputation to explore how missing data would affect our results [37]. We modeled the worst-case scenario as an extreme case where all missing cases started with perfect adherence at baseline (a " 0 " in the binary measure) and changed to poor adherence (a " 1 " in the binary measure) in all follow-up assessments, i.e., we assigned the worst possible treatment effect for them. For this reason, the results from these sensitivity analyses can be regarded as a lower bound of the true intervention effects. We compared the results of these sensitivity analyses to our main regression results.

\section{Results}

\section{Sample Characteristics (Table 1)}

We included 400 participants in the analyses: 203 received the food basket plus nutrition education, and 197 received only nutrition education. Three hundred and twenty-nine (82\%) participants ( $88 \%$ of the food basket plus nutrition education group and $76 \%$ of the nutrition education group, $p<0.01)$ completed the 12-month assessment.

At baseline, average time since ART initiation was 3.7 years. Mean CD4 count was 293 cells $/ \mathrm{mm}^{3}$ with $42 \%$ having counts less than or equal to 250 cells $/ \mathrm{mm}^{3}$, and $9 \%$ were assessed as HIV symptomatic. However, about $23 \%$ of participants were missing CD4 count at baseline. Participants in the food basket plus nutrition education group were more likely to be female, have children and be HIV symptomatic, but less likely to identify as Afrodescendent, have completed primary school, have worked in the last month, and be receiving material support from family or friends.

There was a high prevalence of severe food insecurity among study participants (65\%). Mean BMI was $24 \mathrm{~kg} /$ $\mathrm{m}^{2}$, with $58 \%$ of participants classified in the normal range, $31 \%$ overweight, and $11 \%$ underweight. Food insecurity and being overweight overlapped for many of the participants, as $31 \%$ of those with severe food insecurity were also overweight or obese. The food basket plus nutrition education group had a higher rate of severe food insecurity (72 vs. $58 \% ; p<0.01$ ) compared to the nutrition education only group, but the groups did not differ on BMI. 
Table 1 Baseline sample characteristics by intervention group
$* * * p<0.01$; ** $p<0.05$;

$* p<0.10$

a $n=386$

b $n=361$

${ }^{\mathrm{c}} n=307$

\begin{tabular}{|c|c|c|c|}
\hline & $\begin{array}{l}\text { Food basket+nutrition } \\
\text { education }(n=203)\end{array}$ & $\begin{array}{l}\text { Nutrition } \\
\text { education } \\
\text { only }(n=197)\end{array}$ & All $(n=400)$ \\
\hline \multicolumn{4}{|l|}{ Socio-demographics } \\
\hline Afrodescendent, $\%$ & $4 * * *$ & $19 * * *$ & 12 \\
\hline Female, \% & $74 * * *$ & $62 * * *$ & 69 \\
\hline Primary school or more, $\%$ & $49 * *$ & $58 * *$ & 54 \\
\hline Age in years, mean (SD) & $40(0.70)$ & $41(0.68)$ & $40(0.49)$ \\
\hline $\mathrm{HH}$ w/children $<18$ years old, $\%$ & $87 * * *$ & $77 * * *$ & 82 \\
\hline Worked in last month, \% & $33 * *$ & $44 * *$ & 38 \\
\hline Receives material support, $\%$ & $28 *$ & $35^{*}$ & 32 \\
\hline \multicolumn{4}{|l|}{ HIV-related health status } \\
\hline CD4 count $\left(\right.$ cells $\left./ \mathrm{mm}^{3}\right)$, mean $(\mathrm{SD})$ & $328(178)^{* *}$ & $260.7(167.5)^{* *}$ & $293(175.6)$ \\
\hline HIV symptomatic, $\%$ & $12 * *$ & $6^{* *}$ & 9 \\
\hline Years receiving ART, mean (SD) & $3.6(0.18)$ & $3.8(0.19)$ & $3.7(0.13)$ \\
\hline \multicolumn{4}{|l|}{ Mental health } \\
\hline Depression score, mean (SD) & $6.32(5.24)$ & $5.90(4.89)$ & $6.11(5.07)$ \\
\hline \multicolumn{4}{|l|}{ Household food insecurity } \\
\hline Severe insecurity, $\%$ & $72 * * *$ & $58 * * *$ & 65 \\
\hline Moderate insecurity, $\%$ & 22 & 26 & 24 \\
\hline Mild insecurity, \% & $5^{* * *}$ & $15^{* * * *}$ & 10 \\
\hline No insecurity, \% & $0^{*}$ & $1^{*}$ & 1 \\
\hline \multicolumn{4}{|l|}{ Body mass index (BMI) } \\
\hline Mean BMI, mean (SD) & $23(4.3)$ & $24(4.7)$ & $24(4.5)$ \\
\hline \multicolumn{4}{|l|}{ Adherence (in last months) } \\
\hline Missed appointment, $\%^{\mathrm{a}}$ & $65.2^{*}$ & $55.9 *$ & 60.6 \\
\hline Late picking up meds, $\%^{\mathrm{b}}$ & $63.8 * * *$ & $36.4 * * *$ & 50.4 \\
\hline Missed ART doses $\%^{\mathrm{c}}$ & 41.0 & 45.4 & 43.0 \\
\hline
\end{tabular}

Baseline Adherence

There were missing data for all three adherence measures at baseline: $3.5 \%$ missing values $(n=14)$ for missed clinic appointments, $9.8 \%(n=39)$ for delayed pharmacy refills, and $23.3 \%(n=93)$ for self-reported missed ART doses. At baseline, $60.6 \%$ of the eligible sample had missed at least one clinic appointment in the last 6 months, with the food basket plus nutrition education group being slightly more likely to have missed an appointment ( 65.2 vs. $55.9 \% ; p<0.10)$. Half of the eligible sample $(50.4 \%)$ had delayed refilling their ART prescriptions over the 6 months prior to baseline, including nearly two-thirds of food basket plus nutrition education group $(63.8 \%)$ compared to just over a third $(36.4 \%)$ of the nutrition education group $(p<0.001)$. Forty-three percent of the eligible sample reported having missed taking their ART at some point during the prior month at baseline; rates did not differ significantly between the two intervention groups.
Change in Adherence over 12 months of Receiving the Intervention

\section{Missed Appointments}

In bivariate analyses, the proportion of participants in the food basket plus nutrition education group missing an appointment in the last 6 months decreased significantly from baseline $(63.5 \%)$ to month $6(18.8 \% ; p<0.01)$, with no further change at month 12 . In the nutrition education only group, the proportion of participants missing an appointment in the last 6 months also decreased from baseline $(53.4 \%)$ to month $6(14.9 \% ; p<0.01)$, and further at month $12(3.3 \% ; p<0.01)$ (see Fig. 1a). This trend was maintained for both groups in adjusted regression analyses (Table 2), with 38.0 and $50.4 \%$ fewer participants having missed appointments at month $6(p<0.01)$ and month 12 , respectively, compared to baseline. The coefficients on the interaction terms were not significant, indicating no additional effect of the food basket on 


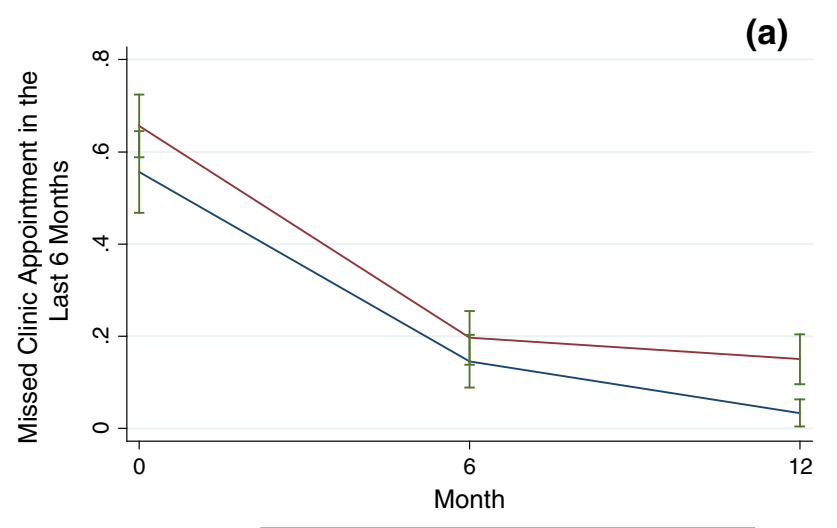

Nutritional counseling only $\longrightarrow$ Basket
$95 \% \mathrm{Cl}$
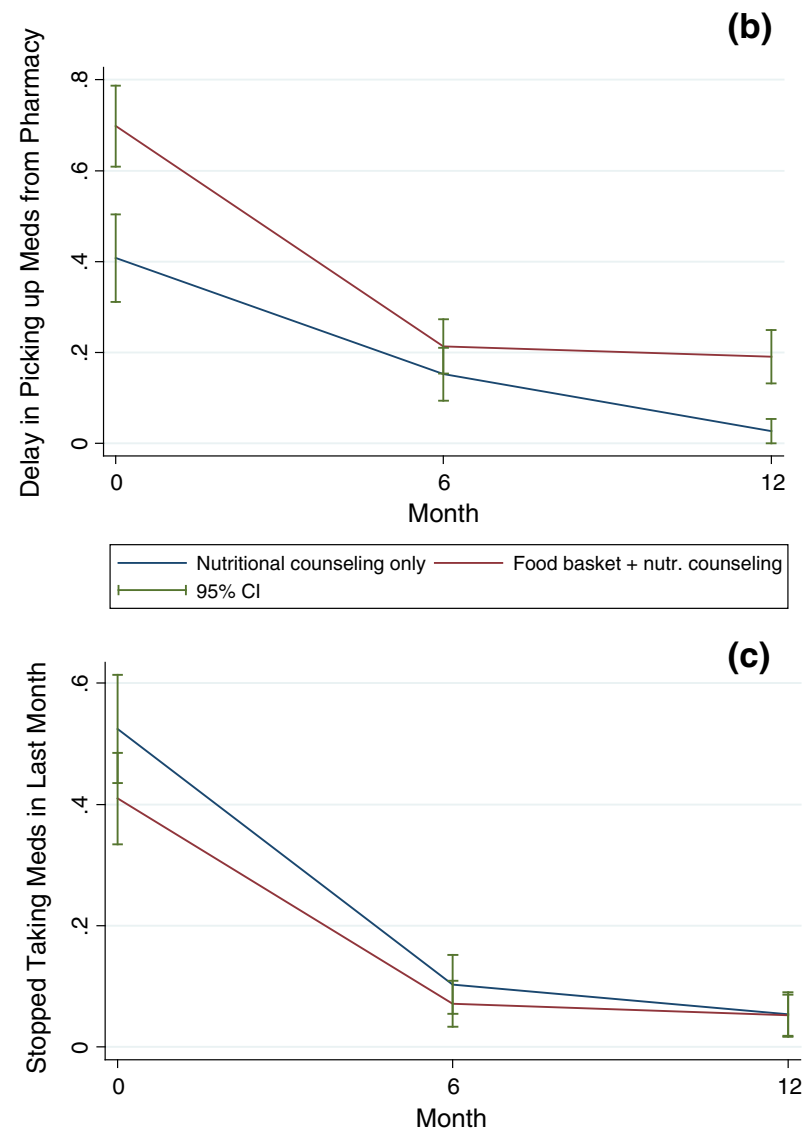

Nutritional counseling only — Food basket + nutr. counseling $95 \% \mathrm{Cl}$

Fig. 1 Trends in adherence over 12 month follow-up, by measure of adherence and intervention group (Unadjusted) a. Missed appointments in last 6 months (Center report) b. Delay in picking up ART (pharmacy report) c. Self-reported missed doses over the past month (patient report)

adherence to scheduled appointments. When we conducted a sensitivity analysis to account for missing data on missed appointments using a 'worst-case scenario' approach, our results were similar to our main model (not shown in table; full models available from the authors upon request).

\section{Delayed Prescription Refills}

In bivariate analyses, the food basket plus nutrition education group experienced a significant decrease in refill delays from baseline $(62.5 \%)$ to month 6 (22.6\%; $p<0.01$ ), with no further change at month 12 . The nutrition education only group had a significant decrease in refill delays from baseline $(33.3 \%)$ to month $6(16.7 \%$; $p<0.01)$, and then a further decrease at month $12(2.7 \%$; $p<0.01$ ) (see Fig. 1b). In multivariate analyses (Table 2), the nutrition education only group had $22.1 \%$ fewer pharmacy refill delays at month $6(p<0.01)$ and $32.5 \%$ fewer delays at month $12(p<0.01)$. Negative and significant coefficients for the interaction terms indicate that, in addition, the food basket plus nutrition education group experienced a $19.6 \%$ larger improvement at month 6 $(p<0.01)$ and an $11.1 \%$ larger improvement at month 12 $(p<0.10)$, compared to the nutrition education only group. In a sensitivity analysis to account for missing data on pharmacy refill delays using a 'worst-case scenario' approach, our results were similar to those from the main model (not shown in table; full models available from the authors upon request).

\section{Self-Reported Missed ART Doses}

In bivariate analyses, the proportion of food basket plus nutrition education participants that reported missed doses in the last month decreased significantly from baseline $(40.4 \%)$ to month $6(6.6 \% ; p<0.01)$, with no further change at 12 months. In the nutrition education only group, the proportion of participants that missed doses or interrupted ART in the last month decreased significantly from baseline $(45.0 \%)$ to month $6(9.2 \% ; p<0.01)$, with a further decrease at month $12(5.4 \% ; p<0.05)$ (see Fig. 1c). In multivariate analyses, this trend was maintained for both groups, with 34.4 and $41.4 \%$ fewer study participants reporting having missed doses or interrupted ART in the last 6 months at month 6 and month 12 , respectively, compared to baseline $(p<0.01$ for both results). The coefficients on the interaction terms were not statistically significant, indicating no additional effect of the food basket on reducing ART interruptions. In a sensitivity analysis using a 'worst-case scenario' approach to account for missing data on self-reported missed doses or ART interruption, results were attenuated but still statistically significant: 20.0 and $27.3 \%$ fewer study participants would have missed doses or interrupted ART in the last 6 months at month 6 and month 12, respectively ( $p<0.01$ for both results) (not shown in table; full models available from the authors upon request). 
Table 2 Longitudinal regression analysis of intervention effects on adherence outcomes

Model results are from population-averaged linear probability regression model. All regressions include month of interview indicators to control for seasonality (coefficients not shown)

${ }^{\text {a }}$ Numbers reported are coefficients and numbers in parenthesis correspond to standard errors

$* * * p<0.01$; ** $p<0.05$; $* p<0.10$

\begin{tabular}{lccc}
\hline Variables & $\begin{array}{l}\text { Missed } \\
\text { Appointment } \\
\text { (observations }=990)\end{array}$ & $\begin{array}{l}\text { Delayed pharmacy } \\
\text { Refills } \\
\text { (observations }=963)\end{array}$ & $\begin{array}{l}\text { Self-reported } \\
\text { Missed ART doses } \\
\text { observations }=911)\end{array}$ \\
\hline Food basket & $0.094(0.050)^{*}$ & $0.251(0.052)^{* * *}$ & $-0.047(0.056)$ \\
Month 6 & $-0.380(0.044)^{* * *}$ & $-0.221(0.048)^{* * *}$ & $-0.344(0.053)^{* * *}$ \\
Month 12 & $-0.504(0.039)^{* * *}$ & $-0.325(0.040)^{* * *}$ & $-0.414(0.047)^{* * *}$ \\
Food basket $\times$ month 6 & $-0.046(0.060)$ & $-0.196(0.062)^{* * *}$ & $0.005(0.066)$ \\
Food basket $\times$ month 12 & $0.012(0.060)$ & $-0.111(0.059)^{*}$ & $0.050(0.063)$ \\
Baseline covariates & & & $-0.004(0.002)^{* *}$ \\
Age & $-0.004(0.001)^{* * * *}$ & $0.001(0.001)$ \\
Female & $-0.039(0.034)$ & $-0.008(0.033)$ & $-0.062(0.029)^{* *}$ \\
Primary school or more & $-0.038(0.028)$ & $-0.149(0.030)^{* * * *}$ & $0.008(0.025)$ \\
Worked in last month & $-0.010(0.030)$ & $-0.008(0.031)$ & $-0.007(0.026)$ \\
HIV symptomatic & $-0.014(0.056)$ & $-0.029(0.063)$ & $0.017(0.049)$ \\
Children $<$ age 18 in household & $0.009(0.008)$ & $0.009(0.009)$ & $-0.009(0.008)$ \\
Severe food insecurity & $0.013(0.029)$ & $0.033(0.032)$ & $0.036(0.025)$ \\
Body mass index & $0.001(0.003)$ & $-0.003(0.004)$ & $0.006(0.003)^{*}$ \\
Support from family/friends & $-0.040(0.029)$ & $-0.021(0.031)$ & $-0.025(0.027)$ \\
Depression score & $-0.001(0.003)$ & $0.006(0.003)^{*}$ & $0.005(0.003)^{*}$ \\
Constant & $0.765(0.124)^{* * *}$ & $0.642(0.138)^{* * *}$ & $0.374(0.116)^{* * *}$ \\
\hline
\end{tabular}

\section{Discussion}

This is the first prospective clinical trial to test the effects of a nutrition intervention on ART adherence among adults living with HIV in Latin America, and the first to our knowledge in a cohort with a high proportion of overweight or obese ART patients. We found that treatment adherence improved significantly among study participants, all of whom received nutrition education as part of best practices to offer nutritional support for HIV, with one intervention group receiving also a food basket meant to ease household resource constraints and increase food availability to the person receiving ART. The largest improvements in adherence occurred in the first 6 months of the study, although in some cases there was further improvement at 12 months. Contrary to our hypotheses, we did not observe an additive effect of the food basket with regard to reducing missed clinic appointments and missed ART doses, as both groups displayed similar improvement. However, the food basket did reduce delays in prescription refills.

Other published studies have also found a positive effect of WFP-supported food assistance on food security and adherence to ART. Cantrell et al. [11] conducted a nonrandomized pilot study of food supplementation in Zambia, in which monthly food rations provided by WFP for 6 months were linked to a community health worker-based home visit program to monitor and encourage ART adherence. The authors found that adherence to ART was higher among patients who received the food basket compared to controls, with no associated clinical benefit. The food rations were distributed at the clinics at the time of scheduled follow-up visits, thus representing a strong motivator for participants to attend their appointments. In a cohort of HIV+adult individuals in Haiti who received a family food basket offered for 12 months, similar to the one provided in the present study, Ivers et al. [19] found that food security and timely clinic attendance improved in the food assistance group compared to a non-food assistance comparison group. Another study in Zambia, conducted by Tirivayi et al. [38], found that a food basket provided at the clinic for 12 months to HIV-infected adults on long-term ART had a positive effect on patients seeking timely ART refills. This study found no effect on weight gain or CD4 lymphocyte count. Serrano et al. conducted an evaluation of clinical outcomes and survival rates among patients in Nigeria, recently under ART therapy, who received a food basket for 6 months [12]. In this study, patients in the intervention group received nutritional advice, encouraging them to eat their habitual amount of food plus the provided food basket. The control group was selected retrospectively in the same clinic, applying the same clinical criteria as for the intervention group. Patients in the control group were advised to increase their food intake as much as tolerated and economically possible, but were not provided any extra food. Patients receiving the food basket improved their adherence compared to controls, and showed an increase of 1.7 in CD4 cell count and a reduction in mortality (from 16.9 to $3.2 \%$ ), all statistically significant. 
However, there is one study that found a negative effect of a WFP food basket on ART adherence, assessed by a pharmacy adherence measure (pill pick up) [39]. This was a retrospective evaluation of the effect of an individual food basket offered to adult patients in Mozambique for an initial period of 3 months, with the option to remain in the program for an additional 3-6 months if nutritional status had not improved. Patients attending clinics in five districts in Sofala province were selected at random and compared to a control group selected with similar criteria from a nearby province, Zambezia. However, the groups differed by gender, age, marital status, educational level and occupation. Average length of food assistance provided was 7 months. This study found that food assistance recipients were less adherent to ART than the control group, and that worse adherence was associated with being female, less than 39 years old, unmarried or married, with no formal education and secondary education categories, not at work, and a larger household size. This study presented several caveats, including the retrospective nature of the analysis, lack of evaluation of program implementation, lack of assessment about comparability of quality of pharmacy data, as well as the lack of data related to clinical outcomes.

Our study had several strengths. This is one of the first studies of HIV-affected populations in Latin America that has focused on interventions to improve adherence. The low prevalence of undernutrition $(11 \%)$ and relatively high mean BMI $\left(24 \mathrm{~kg} / \mathrm{m}^{2}\right)$ and prevalence of overweight/ obesity (31\%), compared to previous studies $[12,16,17$, 40], allowed us to test whether food aid and nutrition education would be effective at improving adherence in a context of high food insecurity and among patients with varied nutritional statues. In addition, the majority of our participants were treatment-experienced (3.7 years on average), in contrast with other published studies examining the effect of food aid on HIV outcomes after ART initiation $[12,16,17,41]$.

The conceptualization, design and application of the nutrition education curriculum was developed following the concept that to offer appropriate counsel and guidance on how to improve and maintain a good diet, it is essential to document current dietary intake, assess dietary adequacy, and identify locally available and culturally acceptable foods that may diversify and complement current diets. Following the constructs of the IMB model, we expected that the information provided about the need and how to improve nutritional status as part of the comprehensive management of HIV would increase awareness about the importance of adhering to treatment, leading to an increased personal motivation to comply with this behavior. In the case of the group receiving the family food basket corresponded to the social motivation, which should further reinforce the desired conduct. The third construct of the model refers to behavioral skills, which should translate into better eating habits. According to our hypothesis, the provision of the food basket should make it easier to put in practice these better habits. In our study, we found that treatment adherence improved significantly among study participants as measured by three complementary measures of adherence. Changes were more significant between baseline and 6 months than between 6 and 12 months, although in some cases there was further improvement in adherence at 12 months. Contrary to our hypotheses, we did not observe an additive effect of the food basket with regard to missed appointments and self-reported missed ART doses, as both the food basket and nutrition education group and the nutrition education only group displayed similar improvement. However, delays in prescription refills were reduced more for the group that also received the food basket. This result was sustained even after conducting a worst-case scenario analysis to account for missing data at baseline.

Our study also had several caveats. The study was funded as a pilot project, so we had a small numbers of Comprehensive Care Centers, which presented several challenges. Cluster-adjustments or other approaches to take into account the fact that randomization was done at the Center level (e.g. multilevel modeling) do not perform well with a small numbers of clusters and would produce misleading results, potentially underestimating standard errors [41, 42]. Yet, failing to adjust for clustering may also underestimate standard errors [43]. Therefore, our results should be taken as preliminary and tested in larger samples with more clusters or where randomization at the individual level is possible. In addition, randomization at the clinic level failed to produce statistically comparable groups despite our efforts to include two matched sets of seemingly comparable facilities, so a number of sociodemographics differentiated the intervention groups at baseline. However, we still found whole group significant trends in improved adherence. There is also the possibility of omitted variables, which could bias our results (including in the null direction). A further caveat of our study design was that, in the absence of a control group receiving no intervention, we could not formally test the effect of nutrition education alone on adherence. Although we saw adherence improve among the nutrition education only group, we cannot rule out that secular trends or exogenous changes in the environment were responsible for improvements. Some of the larger effects that we observed, like the reduction in self-reported missed ART doses, may have been the result of a Hawthorne effect (an improvement in human behavior in response to the fact that participants know they are being studied) [44]. However, both our groups were subject to an intervention, and our 
results were sustained over a year, which argues against this possibility. We also recognize that there is a constellation of factors, besides food insecurity, that affect adherence to ART, and we only accounted for some of them. Other factors, including family relationships and support or ART regimen, were not measured, and thus cannot be accounted for in our analysis. As a last point, while our outcome measures relate to treatment adherence more broadly, they do not capture whether or not the patient actually took the antiretroviral medication as prescribed and thus are only proxies for ART medication adherence. However, the use of three different and complementary measures of adherence may also be regarded as a strength, particularly as each of the three measures showed similar trends over the course of the study across all four locations and between study groups, lending support to the assumption that they are valid indicators of ART adherence.

Mention apart is warranted to the development and implementation of a nutrition education program as part of best clinical practices to offer comprehensive treatment for HIV. As previously mentioned, the development of this component of the intervention was based on substantive formative research, and followed a "bottom-up" approach, i.e., building up from understanding our target population's, needs, beliefs and practices, to ground it solidly on them. A recent review of the literature has identified surprisingly limited evidence regarding the effects of nutrition education or counseling on health outcomes among HIVinfected adults [17]. Also, none of the articles selected in this literature review was carried out in Latin America, further underscoring the dearth of information on this topic in this region. Kaye and Moreno-Leguizamon highlight a series of issues that have to be considered when developing culturally appropriate nutrition education interventions, which include: tailoring content to the cultural context of the target population; incorporating local knowledge, expertise and lifestyle choices; distributing or promoting culturally appropriate food; and adapting the intervention to the target population's educational level [17]. All of these points were addressed in the current study's intervention, thus contributing to the acceptability of the program.

Our results have program and policy relevance on several fronts. From a programmatic point of view, this study contributes to evidence that WFP has collected in different locations about the role that food aid may play in promoting/sustaining ART adherence [11, 12, 19, 38]. As noted, previous studies have included mostly participants in early stages of HIV, with under-nutrition as the most prevalent condition, and have provided different variants of food aid, but with no structured nutrition education component included. At least in some of these cases, the effect of food aid on improving clinical outcomes (i.e., survival) has been explained through the increased macronutrient intake [12] rather that by alleviating the pressing need of alleviating household food insecurity. In contrast, our study included participants with a range of nutritional statuses (from underweight to obese), a high prevalence of food insecurity $(65 \%)$, compromised HIV status (mean CD4 cell count at baseline was $297 \mathrm{cell} / \mathrm{mm}^{3}$ ), at all stages of ART and several years under ART (mean 3.7 years), and with poor adherence (40-60.6\%, depending on the measure of adherence). The fact that we observed that the greatest improvement in adherence at 6 months in comparison to 12 months post-intervention may help design exit or transition strategies as complementary interventions that, on the whole, aim to improve the livelihood of PLHIV. Other experiences in Africa also support a positive link between 6-month food aid and increased adherence to ART $[12,38]$. In assessing the role of family food assistance, the content of the food basket in environments such as the one described in this Latin American country, where overweight and obesity are more prevalent than wasting, may need a reappraisal, as the type of foods provided has mostly been targeted to areas in which under-nutrition is the norm and high-energy foods may be more desirable. Also, the cost-benefit of providing a food basket in contrast with nutrition education by itself should also be evaluated, as rising food prices has been documented as a barrier to providing food aid in the context of HIV treatment and care [45]. From the point of view of establishing best practices for comprehensive care to PLHIV, the experiences gained from this study in designing and implementing a nutrition education component may also be of interest. In particular, for the Ministry of Health in Honduras, a key partner institution on this study, these results may be relevant to help them plan for the inclusion of nutrition education activities as part of the regular comprehensive care provided at their HIV centers, as has been recommended by different authors and institutions [14, 17]. In so doing, taking into consideration the cultural context in which the intervention is to take place is crucial, as is the selection of locally available and culturally acceptable foods that fall within the budget of the target population.

Acknowledgments This study was funded by NIMH R34MH084675. Dr. Palar received salary support from AHRQ T32HS00046. The authors want to acknowledge the enthusiastic support received from the civil society represented by the community of participants, family members and support social network of people living with HIV/AIDS in Honduras, who enthusiastically embraced this project and made ample use of the educational resources offered. The collaboration, continued support, and interest for an upscale intervention shown by the Honduras Ministry of Health, through their Department of HIV/AIDS is also gratefully acknowledged. 


\section{References}

1. Deribe K, Hailekiros F, Biadgilign S, Amberbir A, Beyene B. Defaulters from antiretroviral treatment in Jimma University Specialized Hospital, Southwest Ethiopia. Trop Med Int Health. 2008;13(3):328-33.

2. Franke M, Murray M, Muñoz M, et al. Food insufficiency is a risk factor for suboptimal antiretroviral therapy adherence among HIV-infected adults in urban Peru. AIDS Behav. 2011;15(7): 1483-9.

3. Marcellin F, Boyer S, Protopopescu C, et al. Determinants of unplanned antiretroviral treatment interruptions among people living with HIV in Yaoundé, Cameroon (EVAL survey, ANRS 12-116). Trop Med Int Health. 2008;13(12):1470-8.

4. Martin A, Palar K, Derose K, Adams J. Food insecurity and nutritional barriers to antiretroviral therapy: lessons from Latin America and the Caribbean. J HIV AIDS Soc Serv. 2011;10(2): 194-214.

5. Weiser S, Tuller D, Frongillo E, et al. Food Insecurity as a barrier to sustained antiretroviral therapy adherence in Uganda. PLoS One. 2010;5(4):357-66.

6. Raiten D, Grinspoon S, Arpadi S. Nutritional considerations in the use of ART in resource-limited settings. Durban, South Africa; 2005. Report No.

7. Tuller DM, Bangsberg DR, Senkungu J, et al. Transportation costs impede sustained adherence and access to HAART in a clinic population in southwestern Uganda: a qualitative study. AIDS Behav. 2010;14(4):778-84.

8. Weiser S, Tsai AC, Gupta R, et al. Food insecurity is associated with morbidity and patterns of healthcare utilization among HIVinfected individuals in rural Uganda. AIDS. 2012;26(1):67-75.

9. Bärnighausen T, Chaiyachati K, Chimbindi N, et al. Interventions to increase antiretroviral adherence in sub-Saharan Africa: a systematic review of evaluation studies. Lancet Infect Dis. 2011; doi:10.1016/S1473-3099(11)70181-5.

10. Thompson MA, Mugavero MJ, Amico KR, et al. Guidelines for improving entry into and retention in care and antiretroviral adherence for persons with HIV: evidence-based recommendations from an international association of physicians in AIDS care panel. Ann Int Med. 2012;. doi:10.7326/0003-4819-156-11201206050-00419.

11. Cantrell R, Sinkala M, Megazinni K, et al. A pilot study of food supplementation to improve adherence to antiretroviral therapy among food-insecure adults in Lusaka, Zambia. J Acquir Immune Defic Syndr. 2008;49(2):190-5.

12. Serrano C, Laporte R, Ide M, et al. Family nutritional support improves survival, immune restoration and adherence in HIV patients receiving ART in developing country. Asia Pac J Clin Nutr. 2010;19(1):68-75

13. WHO. Nutrition Counseling, Care and Support for HIV-Infected Women. Guidelines on HIV-related care, treatment and support for HIV-infected women and their children in resource-constrained settings. Geneva: WHO, 2004.

14. World Health Organization. Essential prevention and care interventions for adults and adolescents living with HIV in resourcelimited settings. Geneva: World Health Organization; 2008.

15. FANTA. HIV/AIDS: a guide for nutritional care and support. Washington, DC: Academy for Educational Development; 2004.

16. World Bank. HIV/AIDS, nutrition and food security: what we can do-a synthesis of international guidance. Washington, DC: World Bank; 2007.

17. Kaye HL, Moreno-Leguizamon CJ. Nutrition education and counselling as strategic interventions to improve health outcomes in adult outpatients with HIV: a literature review. Afr J AIDS Res. 2011;9(3):271-83.
18. Byron E, Gillespie S, Nangami M. Integrating nutrition security with treatment of people living with HIV: lessons from Kenya. Food Nutr Bull. 2008;29(2):87-97.

19. Ivers L, Chang Y, Jerome J, Freedberg K. Food assistance is associated with improved body mass index, food security and attendance at clinic in an HIV program in central Haiti: a prospective observational cohort study. AIDS Res Ther. 2010; 7(33): $1-8$.

20. Martin A, Palar K. HIV/AIDS policy, food and nutrition in Latin America and the Caribbean. Panama City: The World Food Programme; 2011.

21. WHO, UNAIDS, UNICEF. HIV and infant feeding counselling: a training course. Director's guide. Geneva, Switzerland: World Health Organization; 2000.

22. Nutritional care and support for people living with HIV/AIDS in Uganda: guidelines for service providers. Uganda: STD/AIDS Control Programme, Ministry of Health.

23. World Health Organization. Nutrition counselling, care and support for HIV-infected women: guidelines on HIV-related care, treatment and support for HIV-infected women and their children in resource-limited settings. Geneva: World Health Organization, Department of HIV/AIDS and Department of Nutrition for Health and Development; 2004.

24. Fisher J, Fisher W. Changing AIDS-risk behavior. Psychol Bull. 1992;111(3):455-74.

25. Fisher JD, Fisher WA, Shuper PA. The information motivationbehavioral skills model of HIV preventive behavior. In: Diclemente R, Crosby R, Kegler M, editors. Emerging theories in health promotion practice and research. 2nd ed. San Francisco: Jossey Bass; 2009. p. 21-64.

26. Palar, K. Food Security, Livelihoods, and Antiretroviral Therapy for HIV. Evidence for policy in resource-limited settings. Santa Monica, CA: Pardee RAND Graduate School; 2012.

27. Tirivayi N, Groot W. Health and welfare effects of integrating AIDS treatment with food assistance in resource constrained settings: a systematic review of theory and evidence. Soc Sci Med. 2011;73(5):685-92.

28. Anema A, Vogenthaler N, Frongillo E, Kadiyala S, Weiser S. Food insecurity and HIV/AIDS: current knowledge, gaps, and research priorities. Curr HIV/AIDS Rep. 2009;6(4):224-31.

29. Weiser S, Young S, Cohen C, et al. Conceptual framework for understanding the bidirectional links between food insecurity and HIV/AIDS. Am J Clin Nutr. 2011;. doi:10.3945/ajen.111. 012070.

30. Tsai AC, Bangsberg DR, Emenyonu N, et al. The social context of food insecurity among persons living with HIV/AIDS in rural Uganda. Soc Sci Med. 2011;73(12):1717-24.

31. Habicht J. Estandarización de metodos epidemiológicos cuantitativos sobre el terreno; Standardization of quantitative epidemiological methods in the field. Bol Of Sanit Panamer. 1974;76(5):375-84.

32. World Health Organization. BMI classification, Geneva. http:// apps.who.int/bmi/index.jsp?introPage=intro_3.html. Accessed 17 Apr 2012.

33. Kroenke K, Spitzer RL, Williams JBW. The PHQ-9: validity of a brief depression severity measure. J Gen Int Med. 2001;16(9): 606-13.

34. Melgar-Quiñonez H, Alvarez Uribe M, Fonseca Centeno Z, et al. Características Psicométricas de la Escala de Seguridad Alimentaria ELCSA aplicada en Colombia, Guatemala y México. Segur Alimentar Nutric. 2010;17(1):48-60.

35. Thirumurthy H, Pop-Eleches C, Habyarimana J, Goldstein M, Graff Zivin J. Behavioral responses of patients in AIDS treatment programs: sexual behavior in Kenya. Forum Health Econ Policy. 2012;15(2):1-29. 
36. Zeger SL, Liang KY, Albert PS. Models for longitudinal data: a generalized estimating equation approach. Biometrics. 1988;44: 1049-60.

37. Sterne JAC, White IR, Carlin JB, et al. Multiple imputation for missing data in epidemiological and clinical research: potential and pitfalls. BMJ. 2009;338:3293.

38. Tirivayi N, Koethe J, Groot W. Clinic-based food assistance is associated with increased medication adherence among HIVinfected adults on long-term antiretroviral therapy in Zambia. J AIDS Clinic Res. 2012;3(7):171.

39. Posse M, Tirivayi N, Saha U, Baltussen R. The effect of food assistance on adherence to antriretroviral therapy among HIV/ AIDS patients in Sofala Province, in Mozambique: a retrospective study. J AIDS Clin Res. 2013;4:198.
40. Anema A, Vogenthaler N, Frongillo E, Kadiyala S, Weiser S. Food insecurity and HIV/AIDS: current knowledge, gaps, and research priorities. Cur HIV/AIDS Rep. 2009;6(4):224-31.

41. Gibbons R, Hedeker D, DuToit S. Advances in analysis of longitudinal data. Ann Rev Clin Psychol. 2010;6:79.

42. Bell R, McCaffrey D. Bias reduction in standard errors for linear regression with multi-stage samples. Surv Methods. 2002;28(2): $169-82$.

43. Gibbons RD, Hedeker D, DuToit S. Advances in analysis of longitudinal data. Annu Rev Clin Psychol. 2010;6:79.

44. Franke RH, Kaul JD. The Hawthorne experiments: first statistical interpretation. Am Sociol Rev. 1978;43:623-43.

45. Sztam KA, Fawzi WW, Duggan C. Macronutrient supplementation and food prices in HIV treatment. J Nutr. 2010;140(1):213S-23S. 